\title{
Explanatory perfectionism: A fresh take on an ancient theory
}

\author{
Michael Prinzing \\ ORCID: 0000-0002-7879-7131 \\ michael@prinzing.net
}

The 'Big 3' theories of well-being-hedonism, desire-satisfactionism, and objective list theory-attempt to explain why certain things are good for people by appealing to prudentially good-making properties. But they don't attempt to explain why the properties they advert to make something good for a person. Perfectionism, the view that well-being consists in nature-fulfilment, is often considered a competitor to these views (or else a version of the objective list theory). However, I argue that perfectionism is best understood as explaining why certain properties are prudentially good-making. This version of perfectionism is compatible with each of the Big 3, and, I argue, quite attractive.

Keywords: explanation; eudaimonism; perfectionism; prudential value; welfare; wellbeing

\section{$1 \quad$ Introduction}

Suppose a prestigious journal has just published one of my papers. This is good for me. Those of philosophical temperament will wonder why it's good for me. The 'Big 3' theories of well-being attempt to answer this question. Hedonism claims that it's good for me because it pleases me. Desire-satisfactionism claims that it's good for me because I desire it. Finally, many objective list theories would claim that it is good for me because it is an achievement. Those of deeply philosophical temperaments, however, may be left puzzled by these answers. Why does being pleasant, desired, or an achievement make something good 
for a person? The Big 3, however, have nothing more to say. They purport to explain why certain things are good for a person by positing prudentially good-making properties. But they don't explain why these properties make something good for a person.1

In my view, this makes the theories somewhat unsatisfying. It may initially seem informative to learn that $\mathrm{X}$ is $\mathrm{G}$ because $\mathrm{X}$ has property $\mathrm{Y}$. But it no longer feels very illuminating when one discovers that there is no explanation whatsoever for how Y-ness makes something G. Consider an analogy. 'Why does $\mathrm{X}$ boil at $100^{\circ} \mathrm{C}$ ?' 'Because $\mathrm{X}$ is a sample of water, and water boils at $100^{\circ} \mathrm{C}$.' This is a kind of explanation. But it would feel a great deal less informative if we had no explanation whatsoever for why water boils at $100^{\circ}$

1. As Eden Lin (2017) has persuasively argued—contrary to a recent trend in the literature (Crisp 2017; Fletcher 2013) —each of the Big 3 is both enumerative and explanatory. Each 'enumerates a certain number of good-making properties and uses these properties to explain why certain facts, and not others, are basically good for you' (2017: 69). Different versions of these theories will cash out the properties differently. For instance, desire-satisfactionists might claim that the property is 'being an instance of desire-satisfaction', or 'being desired'. On the latter view, what's good for me is the object of desire (my publishing), and the fact that it's desired explains why it's good. On the former, what's good for me is a conjunctive fact (my publishing and desiring to), and it's the fact that this is an instance of desiresatisfaction that explains why it's good. Such subtleties can be safely ignored for present purposes. The point is that none of these theories attempts to explain why its purportedly good-making property is a good-making property. 
C. If the answer were simply, 'That's just how things are', then the original explanation no longer seems to have provided much understanding.

This worry is the basis for a standard objection to objective list theories. An objective list theory claims that well-being consists in certain objectively valuable goods, for instance: pleasure, knowledge, and achievement. What explains why something is good for a person, on this view, is the fact that it is an instance of one of the list-members. The objection then goes like this: 'Why did these things make it onto the list, but not others? If you simply assert without explanation that pleasure, knowledge, and achievement are good, then you haven't explained much of anything.' In other words, the list seems arbitrary if one has no principled basis for allowing, e.g., pleasure, knowledge, and achievement onto it, while excluding, e.g., virtue and meaning (Bradley 2009; see Fletcher 2013; Rice 2013 for responses to this objection). Of course, the same point can be made against hedonism and desire-satisfactionism. Why does something's pleasantness or being desired—and only its pleasantness or being desired—make it good for a person?

Big 3 defenders can respond that, at some point, explanation just gives out. Guy Fletcher expresses this thought when he writes that 'it's not clear what non-trivial explanation [one] could give' (2013: 218). Fair enough. The buck has to stop somewhere. The question is not whether to stop, but when. Some, like Fletcher, want to stop at the Big 3. Others want to stop at the facts supposedly explained by the Big 3 (e.g., Scanlon 1998: 123-26). If the buck must stop, one might think, then why should it even start? Different people apparently have different intuitions about where explanation bottoms out. Personally, I'm disposed to go as far as possible. (Isn't that what philosophy is all about? 
Philosophers often take seriously why-questions that others dismiss.) In the present case, I think we can go one level further. We can use perfectionism to explain why certain properties are prudentially good-making.2

\section{$2 \quad$ Perfectionism vs. the Big 3}

As I use the term, 'perfectionism' refers to the view that facts about the sort of being that one is (i.e., one's nature) reveal ideals whose fulfilment constitutes one's well-being. In other words, 'certain ideals of well-being are implicit in the way one is constituted. To do well or flourish is to achieve those ideals: to fulfil one's nature' (Haybron 2016: 34). Naturefulfilment can be spelled out in terms of capacity-fulfilment or goal-fulfilment (Haybron 2016; see also Gewirth 2009). That is, it might consist in: the development or exercise of certain capacities (i.e., reaching one's potential); or the realization of certain states that are, so to speak, 'called for' by one's nature (i.e., succeeding qua the kind of being that one is); or some combination of these.

When stated a certain way, perfectionism can seem to be in competition with the Big 3. Compare: 'What's good for a person is whatever satisfies their desires'; and 'What's good for a person is whatever fulfils their nature.' It's also sometimes considered a version of

${ }_{2}$ One putative weakness of perfectionism is that it lacks a natural explanation for prudential bads. If fulfilling one's nature makes something good, then (one might think) not fulfilling one's nature makes it not good. But not being good is different from being bad. I'm unsure how serious this worry is, but lack the space to elaborate. In any case, there are philosophers working on addressing this putative problem (Bradford, ms). 
objective list theory because objective list theorists sometimes buttress their views with perfectionism (e.g., Hurka 1993; Kraut 2007). For instance, objective list perfectionists can respond to the aforementioned arbitrariness worry (Why these goods, and not others?) by claiming that each involves the fulfilment of an aspect of our nature.

However, perfectionism need not be a version of the objective list theory, or even in competition with the Big 3 at all. To see this, let's distinguish between first- and secondorder theories. The former purport to explain why particular things (e.g., getting a prestigious publication or taking a vacation) are good for a person. They answer, 'Why is X good for P?' The latter purport to explain why the good-making properties appealed to in first-order theories are good-making. They answer, 'Why does that make X good for P?' As we've seen, the Big 3 are first-order theories. Perfectionism is most plausibly understood as a second-order theory.

If perfectionism were a first-order theory, it would respond to the question, 'Why was getting a prestigious publication good for me?' with, 'Because it fulfilled your nature'. This claim feels both unintuitive and uninformative. The claim that $\mathrm{X}$ is good for $\mathrm{P}$ when $\mathrm{X}$ fulfils P's nature doesn't tell us anything unless we know what P's nature is and what would fulfil it. Hence, a perfectionist might elaborate, 'Getting that publication involved skilfully exercising your intellectual faculties, which is good for you because it fulfils your nature.' Now it feels like we're on the right track. But notice that this is a two-step explanation, and nature-fulfilment only appears in step two. Getting the publication was good for me because it involved the skilful exercise of intellectual faculties. This makes it good for me because, in virtue of having that property, it fulfils my nature. The first step is (or requires adverting to) 
a first-order theory. The second step, where nature-fulfilment appears, is a second-order theory. The fact that perfectionism is only plausible when one builds in this extra step shows that it is not plausibly understood as a first-order theory, and should instead be understood as a second-order theory.

This explains why perfectionism can be combined with objective list theory. They operate at different levels of explanation. For the same reason, perfectionism is compatible with any first-order theory. To illustrate, consider that a person's values or higher-order desires are often thought to constitute their 'true self' (Frankfurt 1971; Sripada 2016). If that's right, then value-fulfilment theorists (e.g., Tiberius 2018) might claim that fulfilling one's nature involves fulfilling those values/desires. More generally, perfectionist desiresatisfactionists could explain why P's desiring X makes X good for P thusly: 'P, you see, is a desirer. Desirers do well when the objects of their desires obtain-i.e., when their desires are fulfilled-because that's just what success qua desirer involves.' A perfectionist hedonist could similarly explain why pleasing $\mathrm{P}$ makes $\mathrm{X}$ good for $\mathrm{P}$ by appealing to P's nature (Crisp 2006: 103). 'At bottom, $\mathrm{P}$ is a subject of experience. Experiencers do well to the extent that they have good experiences. That's just what success qua experiencer involves. Since the pleasantness of an experience just is the degree to which it is a good feeling, pleasantness is what makes something good for P.' More sophisticated mental state theorists might claim that what's good for a person is happiness because it is the fulfilment of our 'emotional nature' (Haybron 2016: 34). Goal-achievement theorists (e.g., Keller 2004) might 
claim that successfully pursuing one's goals is good for a person because it is the fulfilment of one's nature as an active agent. Et cetera.3

Again, explanation does bottom out somewhere. So, why bother taking the extra explanatory step? One reason is simply because we can. Deeper explanations are better. But, in the next section I will suggest a few additional reasons for advocates of the Big 3 to go perfectionist: (1) many already seem to tacitly assume perfectionist ideas; (2) perfectionist ideas are ubiquitous in public discourse, and may thus reflect a deep feature of how we think about what's good for someone (or something); and (3) building the Big 3 on perfectionist

3 The distinction between first- and second-order theories is relevant to other debates in the literature-e.g., the variabilism debate (Lin 2018; Dorsey 2017). Invariabilists claim that there is a single correct theory of well-being, while variabilists claim that different theories of well-being apply to different kinds of subjects. (For instance, one theory might be true of humans, and another of dogs.) One strategy for defending variabilism involves appealing to perfectionism. Since different subjects can have different natures (e.g., human nature versus canine nature), different theories might apply to different kinds of subjects. Eden Lin has argued that this strategy is self-defeating: 'Perfectionism is a theory of welfare, so the claim that it is true of all welfare subjects cannot support the hypothesis that different theories are true of different subjects' (2018: 332). But Lin fails to distinguish between firstand second-order theories. If the variabilist claimed that no first-order theory is true of all subjects, then they could coherently defend this claim by appeal to perfectionism as a second-order theory. 
foundations reveals a new way of arbitrating between them that may help advance the debate.

\section{$3 \quad$ Why go perfectionist?}

I suspect that the Big 3 gain much of their intuitive plausibility by assuming perfectionist ideas. As we've seen, they are quite easily seen as implying claims about our nature, and objective list theorists do explicitly use perfectionism to rebut objections. Indeed, I think perfectionist intuitions are everywhere, if only implicitly.

One of the considerations sometimes thought to support hedonism is the 'experience requirement' (Bramble 2016; Sumner 1996). This is the claim that, for something to be good or bad for P, it must affect P's experience. Ben Bramble, following L. W. Sumner (1996) and Shelly Kagan (1992), motivates this idea by asserting that 'something that has no effect on a person's experiences does not "touch" or "get to" this person' (2016: 88). The idea is that non-experiential facts are not of the right sort to affect persons. This makes sense if one sees persons as subjects of experience. If that's all there is to us, then for something to affect a person, whether positively or negatively, it must affect their experience. This sounds like perfectionist reasoning: What people are, at bottom, is subjects of experience. Given that this is our nature, the only prudentially relevant facts are those having to do with the exercise of capacities for experience and/or success qua experiencer.

If this is what motivates the experience requirement, it would also explain why many philosophers simply reject the requirement. They don't find it intuitive because they don't believe that people are solely subjects of experience. For example, Antti Kauppinen (2012; 2014) thinks that well-being consists in both an experiential component (happiness), and a 
non-experiential component (meaning). This is because, on his view, we are two kinds of beings: experiencers and agents. 'Meaningfulness is the final good of agents, and happiness the good of experiencers' (2012: 372). Though Kauppinen does not call this view perfectionist, it is clearly a perfectionist version of the objective list theory.

This trend is not a recent development either. Perhaps the most discussed objection to hedonism is the 'philosophy of swine' objection. This is the claim that well-being can't consist in pleasure alone because a good human life is so much richer than that. We can do all kinds of cool and wonderful things besides merely experiencing pleasure. After all, pigs_-beings of a much simpler nature-are equally, if not more, capable of experiencing pleasure. Such a modest account of prudential value, in other words, does not befit our nature. We can even see perfectionist assumptions in J. S. Mill's (1879) famous response to this objection. He argued that humans, unlike swine, are capable of experiencing 'higher pleasures', and the best human lives involve the development and exercise of this capacity.

There are more examples from the philosophical literature (not to mention the psychological literature: Ryan and Deci 2001; Ryff 1989; Ryff and Singer 2008; Waterman 2013). But perfectionist ideas can also be found in public discourse (Bradford 2017). To take just one example, many deaf people don't want their children to receive treatments that would enable them to hear. Some argue that the parents have a right to make this choice. Others object on behalf of the children's well-being, saying that a child is better off hearing. Of course, in many cases, we can be confident that the child will be happy in a closely-knit deaf community. And, by the time they are old enough to make an informed decision, they will have been socialized into that community, and will likely want to remain. But objectors 
aren't persuaded by these responses. If a child's deafness is not treated, they think, the child will miss out on important parts of a rich human life. The most natural way of cashing out the objector's claim is to say that hearing is part of human nature. Moreover, it enables the use of spoken language and the appreciation of music, both of which are distinctively human capabilities. To be deprived of the opportunity to develop and exercise these capacities is intuitively bad for a person. Again, this is clearly the perfectionist intuition at work.

Given this ubiquity, I think perfectionism is not at all a niche philosophical theory, but rather a deep feature of the way in which people think about what is good for a personor really what's good for anything that has a good. When it comes to non-human beings, we tend to think that there are certain species-characteristic ideals whose realization amounts to flourishing (Kraut 2007: 133). For instance, we have a pretty clear sense of what it takes for rose bushes to flourish (literally flowering). For Californian coastal redwood trees to flourish, they must reach several hundred feet in height, which requires living in a cool, foggy climate. Zoologists will tell you that it's good for a wolf to hunt and live in a pack. Et cetera. Given that our thinking about what's good for non-human beings consistently appeals to the nature of the being in question, it would be really strange if our thinking about what's good for human beings disregarded our nature. And, if it's true that perfectionism is a deep feature of ordinary thought, then it's something that should be reflected in philosophical theories. Big 3 theorists could accept this-without giving up on their views - by adopting perfectionism as a second-order theory. 
Finally, having recognized the compatibility between perfectionism and the Big 3, we might be able to use the former to arbitrate between the latter. There tends to be widespread agreement about which things are good for people (e.g., getting a prestigious publication) - despite serious disagreement when it comes to explaining why. Since the Big 3 offer no explanations for their claims about good-making properties, apart from intuition pumping and table thumping, there's no way to arbitrate between them. However, if we are perfectionists, we will see the Big 3 as committed to certain claims about our nature (like the ones suggested in §2), and we can evaluate these theories on the basis of the plausibility of those claims. Are we (perhaps most fundamentally) subjects of experience, agents, valuers, organisms...? Certain views on this question are going to be more plausible than others. So, one way of deciding between the Big 3 would be to get an independent grip on the nature of persons (or 'human nature'), and then use this to decide what makes something good for us. Admittedly, this is also a contentious topic. But, the debate between the Big 3 hasn't really changed much in the past couple millennia. Perhaps a new avenue of approach will grant disputants improved traction.4

4 It's not that nothing has changed. But the standard theories and objections are, broadly speaking, the same as they've always been. The Epicureans and Cyrenaics were hedonists. The aforementioned philosophy of swine objection first appeared in Aristotle (Nicomachean Ethics I 5 1095b20). Desire-/value-satisfactionism was less popular in ancient philosophy, but it was taken seriously enough to merit discussion in Plato's Gorgias and Augustine's De Trinitate. The primary objection, then as now, was that it seems like people can fail to want what's good for them. Aristotle is typically considered an objective list theorist. Today, 
Personally, I am inclined towards a pluralistic view of our nature, which recommends an objective list theory. It seems to me that we are: biological organisms, which is why the proper functioning of our bodies (i.e., health) is good for us; emotional beings, which is why happiness is good for us; rational agents, which is why the successful pursuit of our goals is good for us; social beings, which is why close relationships and community are good for us; etc. Others might have different views. We could imagine a value-fulfilment theorist (e.g., Tiberius 2018) saying something like: 'Sure, we're social, emotional, etc. beings. But there is something deeper, or more fundamental about the fact that we are valuers. Our values are what make us who we are. Thus, value-fulfilment is what really matters.' Personally, I don't find that claim very plausible. But that's precisely the point. This is a new direction from which to approach debates about well-being.

\section{Conclusion}

The Big 3 theories of well-being are first-order theories. They explain why certain things (e.g., getting a prestigious publication or taking a vacation) are good for a person by positing prudentially good-making properties. They don't, however, explain why those properties make something good for a person. Yet each can offer such explanations when paired with perfectionism, which is best understood as a second-order theory that explains

probably the most common objection to such theories is that they are fetishistic: the things on the list are typically good for people, but only insofar as they make people happy, give them what they want, or some such thing. This objection was first raised by the Epicureans (Annas 1987). 
why a property is prudentially good-making by appealing to the nature of the person in question. I suggested three reasons - apart from an increase in explanatory power-for Big 3 theorists to go perfectionist. First, many seem to tacitly assume perfectionism anyway. Second, perfectionist ideas seem to be a deep feature of ordinary thought about well-being, and thus something that philosophical theories should explain. Finally, embracing explanatory perfectionism provides theorists with a new dialectical strategy. Perfectionist versions of the Big 3 are committed to claims about our nature. We could evaluate them by comparing the plausibility of these claims. This may not resolve ancient and perennial debates. But at least it's fresh ground on which to maneuver.5

5 Many thanks to Valerie Tiberius for encouraging me to write this idea down, and for her comments on an early draft. I'd also like to thank Geoff Sayre-McCord for helpful conversations, and the anonymous reviewers at Analysis for their commentary. 


\section{References}

Annas, J. 1987. Epicurus on pleasure and happiness. Philosophical Topics 15: 5-21.

Bradford, G. 2017. Problems for perfectionism. Utilitas 29: 344-64.

ms. Perfectionist bads.

Bradley, B. 2009. Well-Being and Death. Oxford: Oxford University Press.

Bramble, B. 2016. A new defense of hedonism about well-being. Ergo 3: 85-112.

Crisp, R. 2006. Reasons and the Good. Oxford University Press.

- 2017. Well-being. In The Stanford Encyclopedia of Philosophy, edited by Edward Zalta. https://plato.stanford.edu/entries/well-being/.

Dorsey, D. 2017. Why should welfare 'fit'? The Philosophical Quarterly 67: 685-708.

Fletcher, G. 2013. A fresh start for the objective-list theory of well-being. Utilitas 25: 206-20.

Frankfurt, H. 1971. Freedom of the will and the concept of a person. The Journal of Philosophy 68: 520.

Gewirth, A. 2009. Self-Fulfillment. Princeton University Press.

Haybron, D. 2016. The philosophical basis of eudaimonic psychology. In Handbook of Eudaimonic Well-Being, ed. J. Vittersø, 27-53. New York: Springer International Publishing.

Hurka, T. 1993. Perfectionism. Oxford University Press.

Kagan, S. 1992. The limits of well-being. Social Philosophy \& Policy 9: 169-89.

Kauppinen, A. 2012. Meaningfulness and time. Philosophy and Phenomenological Research 84: 345-77.

—. 2014. Meaning and happiness. Philosophical Topics 41: 161-83.

Keller, S. 2004. Welfare and the achievement of goals. Philosophical Studies 121: 27-41.

Kraut, R. 2007. What Is Good and Why: The Ethics of Well-Being. Cambridge, MA: Harvard University Press.

Lin, E. 2017. Enumeration and explanation in theories of welfare. Analysis 77: 65-73. 
- 2018. Welfare invariabilism. Ethics 128: 320-45.

Mill, J. S. 1879. Utilitarianism. 7th ed. London: Longmans, Green.

Rice, C. 2013. Defending the objective list theory of well-being. Ratio 26: 196-211.

Ryan, R., and E. Deci. 2001. On happiness and human potentials: a review of research on hedonic and eudaimonic well-being. Annual Review of Psychology 52: 141-66.

Ryff, C. 1989. Happiness is everything, or is it? Explorations on the meaning of psychological wellbeing. Journal of Personality and Social Psychology 57: 1069-81.

Ryff, C., and B. Singer. 2008. Know thyself and become what you are: a eudaimonic approach to psychological well-being. Journal of Happiness Studies 9: 13-39.

Scanlon, T. 1998. What We Owe To Each Other. Cambridge, MA: Harvard University Press.

Sripada, C. 2016. Self-expression: a deep self theory of moral responsibility. Philosophical Studies 173: $1203-32$.

Sumner, L. 1996. Welfare, Happiness, and Ethics. Oxford University Press.

Tiberius, V. 2018. Well-Being As Value Fulfillment: How We Can Help Each Other to Live Well. Oxford University Press.

Waterman, A., ed. 2013. The Best Within Us: Positive Psychology Perspectives on Eudaimonia. Washington, DC: American Psychological Association. 